\title{
Role of Preoperative CEA, CA 19-9, NLR and PLR as Predictors of Adverse Prognostic Pathological Features of Gastric Carcinoma Patients in a Tertiary Centre of Nepal
}

\author{
Rajesh K Mandal, Ramesh S Bhandari, Paleswan J Lakhey, Yogendra P Singh, Pradeep Vaidya, Prasan \\ BS Kansakar, Bikal Ghimire, Bishnu P Kandel \\ Department of GI and General Surgery, Maharajgunj Medical Campus, Tribhuvan University Teaching Hospital, \\ Maharajgunj, Kathmandu, Nepal
}

\section{Corresponding author:}

\section{Rajesh Kumar Mandal, MBBS, MS}

Department of GI and General Surgery, Maharajgunj Medical Campus, Tribhuvan University Teaching Hospital, Maharajgunj, Kathmandu, Nepal

Email:dr.rajesh23@gmail.com

Submitted : Aug 30, 2019

Accepted : Sept 28, 2019

\begin{abstract}
Introduction

According to GLOBOCAN 2018, gastric carcinoma is the fifth most common cancer (5.7\%) and third most common cause of cancer related death (8.2\%) worldwide. Delayed presentation and advanced disease at diagnosis, owing to the overlapping symptoms, can be attributed to its high mortality. Gastrectomy is one of the most commonly performed surgery at our centre. This study aims to study the role of pre-operative serum carcinoembryonic antigen (CEA), carbohydrate antigen 19-9 (CA 19-9), neutrophil-lymphocyte ratio (NLR) and platelet-lymphocyte ratio (PLR) as predictors of adverse prognostic pathological features of gastric carcinoma patients who were considered for surgery at our centre.
\end{abstract}

\section{Methods}

This is a retrospective analysis of prospectively maintained database of all operated gastric carcinoma patients since June 2016 to January 2019. Various pre-operative variables including serum CEA level, serum CA 19-9 level, NLR and PLR were collected. Intra-operative surgical procedures performed and post-operative pathologic variables like tumor size, stage, grade, lymph node ratio (LNR), lymphovascular invasion (LVI) and perineural invasion (PNI) were collected.

\section{Results}

A total 60 patients were planned for surgical intervention over this duration. Mean age of the population was $56.8 \pm 12.5$ years with slight male predominance (i.e. $55 \%$ ). Mean CEA level was $6.17 \mathrm{ng} / \mathrm{ml}$ and CA $19-9$ level was $72.1 \mathrm{U} / \mathrm{ml}$. The mean NLR and PLR of the study population was 3.4 and 200 respectively. Fifty four patients had distal tumors and six had proximal tumors. Curative surgery was performed in 40 patients out of which 37 underwent subtotal gastrectomy and three underwent total gastrectomy. D2 gastrectomy was performed in 55\% patients treated with curative intention. Advanced disease (T2 and above) was seen in $86.7 \%$ of patients. Preoperative CEA, CA 19-9, NLR, PLR were evaluated for association with pathologic features like tumor size, T stage, grade of tumor, LNR, LVI, and PNI but statistical analysis failed to show any significant association.

\section{Conclusion}

Advanced disease at presentation is common in gastric carcinoma. Preoperative clinical parameters including tumor markers CEA, CA 19-9, NLR and PLR may not be useful to diagnose the advanced disease in gastric carcinoma patients.

Keywords: Gastric carcinoma, gastrectomy, CEA, CA 19-9, NLR, PLR 


\section{INTRODUCTION}

G astric carcinoma (involving cardia and noncardia) remains an important carcinoma worldwide. Over 1,000,000 new cases and an estimated 783,000 deaths (equating to 1 in every 12 deaths globally) are accounted to this carcinoma. Hence it has become the fifth most frequently diagnosed cancer and the third leading cause of cancer death. Men are twice commonly affected. Incidence rates in Eastern Asia are increasing significantly e.g. in Mongolia, Japan and the Republic of Korea, the country with the highest rates worldwide in both sexes. ${ }^{1}$

Gastric carcinoma stomach is relatively evenly distributed with $30 \%$ occurring in the antrum, $30 \%$ in the body and $40 \%$ in the fundus and cardia. ${ }^{2-5}$.

Among the various tumor markers available for gastric carcinoma preoperative serum level of cancer antigen 72-4 (CA 72-4) has the best predictive value in indicating advanced disease. ${ }^{6}$ However serum carcinoembryonic antigen (CEA) and carbohydrate antigen 19-9 (CA 19-9) have been frequently studied in various studies for their role as preoperative assessment as predictors of tumor stage, nodal involvement, recurrence. ${ }^{7.8}$ CEA, CA 19-9 level are measured frequently and easily available at our centre. Assessment of CA 72-4 is not easily available at our centre and in our country. Elevated CEA level has been associated with larger tumor sizes, greater serosal invasion, more frequent lymphatic and vascular involvement and higher rates of lymph node and hepatic metastases than CEA-negative patients. ${ }^{9}$ CEA has been associated with poorly differentiated carcinoma. ${ }^{10}$ Similarly CA $19-9$ has been associated

Table 1. General characteristics of the study group

\begin{tabular}{lc}
\hline \multicolumn{1}{c}{ Variables } & Values $(\mathrm{n}=60)$ \\
\hline Age in years (mean \pm SD) & $56.8 \pm 12.5$ \\
Gender $\mathrm{n}(\%)$ & $33(55 \%)$ \\
Male & $27(45 \%)$ \\
Female & \\
Symptoms $\mathrm{n}(\%)$ & $36(60 \%)$ \\
Pain abdomen & $14(23.3 \%)$ \\
GOO & $8(13.3 \%)$ \\
UGl bleed & \\
Duration of symptoms (in & \\
months) & $7.3 \pm 10.75$ \\
Mean \pm SD & $3(2$ days-2 years) \\
Median (range) & $19.47 \pm 2.66$ \\
BMl in $\mathrm{kg} / \mathrm{m}^{2}($ mean \pm SD) &
\end{tabular}

Table 2. Preoperative variables

\begin{tabular}{lc}
\hline \multicolumn{1}{c}{ Variables } & Values $(\mathrm{n}=60)$ \\
\hline $\begin{array}{l}\text { Total protein in } \mathrm{gm} / \mathrm{l} \\
\text { (mean } \pm \text { SD) }\end{array}$ & $59.9( \pm 10.4)$ \\
Serum albumin in $\mathrm{gm} / \mathrm{l}$ & $34.3( \pm 8)$ \\
(mean \pm SD) & \\
NRI (mean \pm SD) & $88.9( \pm 18.15)$ \\
NLR (mean \pm SD) & $3.4( \pm 2.3)$ \\
PLR (mean $\pm S D)$ & $200( \pm 131.9)$ \\
CEA levels ng/ml & $6.94( \pm 8.11)$ \\
Mean $\pm S D$ & 3.8 \\
Median & $72.13( \pm 101.54)$ \\
CA 19-9levels U/ml & 33.5 \\
Mean $\pm S D$ & \\
Median & \\
\hline
\end{tabular}

with higher tumor depth, lymph nodal involvement, peritoneal metastases and stage. ${ }^{11-13}$

Gastric carcinoma has long been considered as inflammation driven carcinoma. ${ }^{14-16}$ Hence systemic inflammatory changes has been studied extensively. Presence of lymphocytic infiltration at the tumor site delays tumor progression and is associated with better survival. Neutrophilic infiltration in the stroma of tumor is associated with poor prognosis. Presence of platelets at the tumor site promotes tumor growth by enhancing angiogenesis. ${ }^{17}$ Among various parameters neutrophil-platelet ratio and platelet-lymphocyte ratio has been studied commonly. Plateletlymphocyte ratio (PLR) and neutrophil-lymphocyte ratio (NLR) measurements can provide important diagnostic and prognostic results in patients with resectable gastric carcinoma. ${ }^{18}$

In case of curative intention, the surgery involves complete resection with a standardized D2 lymphadenectomy. ${ }^{19}$ For incurable gastric carcinoma patients, palliative resection may improve the quality of life, but it is not recommended in an asymptomatic patient. ${ }^{20}$

Table 3. Distribution of patients on the basis of subgroup division of NLR \& PLR

\begin{tabular}{|c|c|}
\hline Variables & Frequency (\%) \\
\hline \multicolumn{2}{|l|}{ NLR } \\
\hline$<3.40$ & 37 (61.7) \\
\hline$\geq 3.40$ & 23 (38.3) \\
\hline \multicolumn{2}{|l|}{ PLR } \\
\hline$<200$ & $36(60)$ \\
\hline$\geq 200$ & $24(40)$ \\
\hline
\end{tabular}


Table 4. Distribution of pathologic features in the study group

\begin{tabular}{lc}
\hline \multicolumn{1}{c}{ Variables } & $\begin{array}{c}\text { Study group } \\
(\mathbf{n}=60)\end{array}$ \\
\hline Tumor size in cms (mean \pm SD) & $4.3( \pm 1.94)$ \\
T stage Frequency $(\%)$ & \\
T1 & $0(0)$ \\
T2 & $12(20 \%)$ \\
T3 & $22(36.7 \%)$ \\
T4 & $25(41.7 \%)$ \\
T grade Frequency (\%) & \\
Grade 1 & $7(11.7 \%)$ \\
Grade 2 & $20(33.3 \%)$ \\
Grade 3 & $22(36.7 \%)$ \\
Mean numbers of LN retreived & $18( \pm 8.34)$ \\
( \pm SD) & \\
Mean LNR ( \pm SD) & $0.31( \pm 0.28)$ \\
N stage Frequency (\%) & \\
N0 & $10(16.7 \%)$ \\
N1 & $6(10 \%)$ \\
N2 & $26(43.3 \%)$ \\
N3 & $15(25 \%)$ \\
LVI Frequency (\%) & $35(58.3 \%)$ \\
PNI Frequency (\%) & $36(60 \%)$ \\
\hline
\end{tabular}

\section{METHODS}

This is a retrospective study performed at the Department of GI and General Surgery of Tribhuvan University Teaching Hospital (TUTH). Ethical clearance was obtained from Institutional Review Committee (IRC) of Institute of Medicine (IOM). Hospital records of all cases admitted since June 2016 till January 2019 from out-patient department (OPD) and Emergency Department (ED) with the diagnosis of gastric carcinoma were followed. All patients radiologically, endoscopically and/or histopathologically proven carcinoma stomach who were potentially resectable and underwent some form of surgery were included in the study.

Preformed proforma was used to collect data. Preoperative variable: age, gender, symptoms and its duration, serum CEA level, serum CA 19-9 level, $\mathrm{BMI}, \mathrm{NRI}$, Eastern Cooperative Oncology Group (ECOG), endoscopic findings, total protein and serum albumin were collected. Intra-operative surgical procedure and post-operative pathologic variables like tumor size, stage, grade, lymph node ratio, lymphovascular invasion and perineural invasion were collected. SPSS version 25 was used for the analysis. Association of categorical variables was analyzed using chi-square test. $P$ value of 0.05 was considered significant.

\section{RESULTS}

The total number of patients in this duration were 60 , out of which 33 were males. Male to female ratio was 1.22:1. Mean age of the study population was $56.8 \pm 12.5$ years and median age was 59 years with a range of 31-80 years. Mean age of male patients was 59.2 whereas the mean age of female was 53.9 years. Mean age of patients treated with curative intent was $55.1( \pm 12.1)$ years. Nineteen $(47.5 \%)$ out of 40 patients treated with curative intent were female. The highest proportion of patents $(11,18.3 \%)$ fell in the age group of 56 60 years.

Abdominal pain was the most common presenting symptom with $60 \%$ patients had abdominal pain at presentation whereas partial or total gastric outlet obstruction and UGI bleed was present in 23.3 $\%$ and $13.3 \%$ patients respectively. Duration of presentation varied from 2 days to 2 years. Median duration of symptom was 3 months as shown in table 1. Mean body mass index (BMI) was 19.47 $( \pm 2.66)$ in the study group.

Mean total protein level was $59.9( \pm 10.4)$, albumin level was $34.3( \pm 8), 51.7 \%$ patients had total protein value less than the mean value and $53.3 \%$ had serum albumin less than mean value. As shown in table 2. Mean nutritional risk index (NRI) of the patients' overall was $88.9( \pm 18.15)$ suggestive of moderate malnourishment whereas mean BMI was $19.47 \mathrm{~kg} / \mathrm{m} 2$ as shown in table 1 . Of total patients $65 \%$ had NRI $\geq 88.9$ whereas $61.7 \%$ of patients had $\mathrm{BMI}<19.4 \mathrm{~kg} / \mathrm{m} 2$. In patients who received curative treatment had mean $\mathrm{NRI}$ of 90.94 and mean BMl of $19.8 \mathrm{~kg} / \mathrm{m}^{2}$.

Mean carcino-embryonic antigen (CEA) level was $6.94(\mathrm{ng} / \mathrm{ml})( \pm 8.1) .33 .3 \%$ patients had serum CEA level more tha and the mean value. Mean CEA level for patients with curative surgery is 6.17 $(n \mathrm{~g} / \mathrm{ml})$. Mean carbohydrate antigen 19-9 (CA 199) level was $72.13 \mathrm{U} / \mathrm{ml}( \pm 101.5)$ in overall patients. Twenty three percent patients had serum CA 19-9 level more than mean value. For patients treated with curative intent the mean CA 19-9 level was $74.4(\mathrm{U} / \mathrm{ml})$.

Mean neutrophil-lymphocyte ratio (NLR) and platelet-lymphocyte ratio (PLR) was $3.4( \pm 2.3)$ and $200( \pm 131.9)$ respectively. Mean NLR and PLR for patients treated with curative intent was 3.58 and 193.15.

Most of the patients $(37,61.7 \%)$ had NLR $<3.4$. Similarly $36(60 \%)$ patients had PLR of $<200$ as shown in table 3. Majority of patients had ECOG score of 1 and 2 i.e. $48.3 \%$ and $36.7 \%$ respectively. Pre-operative histopathologically proven malignancy was in 46 patients $(76.7 \%)$. 
Table 5. Association of tumor size, stage and grades with preoperative variables

\begin{tabular}{|c|c|c|c|c|c|c|c|c|c|}
\hline & \multicolumn{3}{|c|}{ Tumor size (cms) } & \multicolumn{3}{|c|}{ T stage } & \multicolumn{3}{|c|}{ HPE grade } \\
\hline & $<4(\%)$ & $\geq 4(\%)$ & $\begin{array}{c}\mathrm{P}- \\
\text { value }\end{array}$ & $1(\%)$ & $\begin{array}{c}2,3,4 \\
(\%)\end{array}$ & $\begin{array}{c}\text { P- } \\
\text { value }\end{array}$ & WD (\%) & $\begin{array}{c}\text { PD/MD } \\
(\%)\end{array}$ & $\begin{array}{c}\text { P- } \\
\text { value }\end{array}$ \\
\hline \multicolumn{10}{|l|}{ Age } \\
\hline$<56.8$ & $17(34.7)$ & $12(24.5)$ & 0.65 & $4(7)$ & 29 (50.9) & 0.29 & $5(10.2)$ & 24 (49) & 0.47 \\
\hline$\geq 56.8$ & $13(26.5)$ & 7 (14.3) & & $1(1.8)$ & $23(40.4)$ & & $2(4)$ & $18(36.7)$ & \\
\hline \multicolumn{10}{|l|}{ Sex } \\
\hline Male & 19 (38.8) & 7 (14.3) & 0.70 & $3(5.3)$ & $28(49.1)$ & 0.79 & $6(12.2)$ & $20(40.8)$ & 0.06 \\
\hline Female & $11(22.4)$ & $12(24.5)$ & & $2(3.5)$ & $24(42.1)$ & & $1(2.0)$ & 22 (44.9) & \\
\hline \multicolumn{10}{|l|}{$\begin{array}{l}\mathrm{CEA}^{*} \\
(\bigotimes \mathrm{g} / \mathrm{ml})\end{array}$} \\
\hline$<3.8$ & 23 (46.9) & 7 (14.3) & 0.31 & $4(7)$ & 34 (59.6) & 0.51 & $4(8.2)$ & 31 (63.2) & 0.36 \\
\hline$\geq 3.8$ & 7 (14.3) & 19 (38.80 & & $1(1.8)$ & 18 (31.6) & & $3(6.1)$ & $11(22.5)$ & \\
\hline \multicolumn{10}{|l|}{$\begin{array}{l}\text { CA19-9* } \\
\text { (U/ml) }\end{array}$} \\
\hline$<33.5$ & $24(49)$ & 15(30.6) & 0.93 & $1(1.8)$ & $30(52.6)$ & 0.17 & $2(4)$ & $25(51)$ & 0.13 \\
\hline$\geq 33.5$ & $6(12.2)$ & $4(8.2)$ & & $4(7)$ & 22 (38.6) & & $5(10.2)$ & $17(34.7)$ & \\
\hline \multicolumn{10}{|l|}{ NLR } \\
\hline$<3.40$ & 16 (32.65) & $12(24.5)$ & 0.49 & $4(7)$ & $30(52.6)$ & 0.33 & $4(8.2)$ & $24(49)$ & 0.37 \\
\hline$\geq 3.40$ & 14 (28.6) & 7 (14.3) & & $1(1.8)$ & 22 (38.6) & & $3(6.1)$ & $18(36.7)$ & \\
\hline \multicolumn{10}{|l|}{ PLR } \\
\hline$<200$ & $20(40.8)$ & $10(20.4)$ & 0.33 & $4(7)$ & $31(54.4)$ & 0.37 & $6(12.2)$ & $24(49)$ & 0.15 \\
\hline$\geq 200$ & $10(20.4)$ & $9(18.4)$ & & & & & $1(2)$ & $18(36.7)$ & \\
\hline
\end{tabular}

* Owing to the non-normal distribution of data, median used for analysis

Table 6. Association of LNR, LVI and PNI with preoperative variables

\begin{tabular}{|c|c|c|c|c|c|c|c|c|c|}
\hline & \multicolumn{3}{|c|}{ LVI } & \multicolumn{3}{|c|}{ LNI } & \multicolumn{3}{|c|}{ PNI } \\
\hline & $<0.3(\%)$ & $\geq 0.3(\%)$ & $\begin{array}{c}\mathrm{P}- \\
\text { value }\end{array}$ & Yes (\%) & No (\%) & $\begin{array}{c}\mathrm{P} \text { - } \\
\text { value }\end{array}$ & Yes (\%) & No (\%) & $\begin{array}{c}\mathrm{P}- \\
\text { value }\end{array}$ \\
\hline Age & & & & a & & & & & \\
\hline$<56.8$ & 15 (31.2) & $14(29.1)$ & 0.67 & $22(45.8)$ & 7 (14.6) & 0.57 & $22(45.8)$ & 7 (14.5) & 0.87 \\
\hline$\geq 56.8$ & $11(22.90$ & 8 (16.6) & & $13(27)$ & 6 (12.5) & & $14(29.1)$ & $5(10.4)$ & \\
\hline \multicolumn{10}{|l|}{ Sex } \\
\hline Male & $14(29.1)$ & $12(25)$ & 0.96 & '19 (39.6) & 7 (14.6) & 0.98 & 19 (39.6) & $7(14.5)$ & 0.74 \\
\hline Female & 12 (25) & $10(20.8)$ & & 16 (33.3) & $6(12.5)$ & & 7 (14.5) & $5(10.4)$ & \\
\hline \multicolumn{10}{|l|}{$\begin{array}{l}\text { CEA }^{*} \\
(\otimes g / m l)\end{array}$} \\
\hline$<3.8$ & 19 (39.6) & 15(31.2) & 0.71 & 23 (47.9) & $11(22.9)$ & 0.20 & $24(50)$ & $10(20.8)$ & 0.27 \\
\hline$\geq 3.8$ & $7(14.6)$ & $7(14.6)$ & & $12(25)$ & $13(27)$ & & $12(25)$ & $2(4.16)$ & \\
\hline \multicolumn{10}{|l|}{$\begin{array}{l}\text { CA19-9* } \\
(\mathrm{U} / \mathrm{ml})\end{array}$} \\
\hline$<33.5$ & $21(43.7)$ & $17(35.4)$ & 0.76 & $26(54.1)$ & $12(25)$ & 0.17 & $27(56.2)$ & $11(22.9)$ & 0.22 \\
\hline$\geq 33.5$ & $5(10.4)$ & 5 (10.4) & & 9 (18.7) & $1(2)$ & & 9 (18.7) & $1(2)$ & \\
\hline \multicolumn{10}{|l|}{ NLR } \\
\hline$<3.40$ & 15 (31.2) & $12(25)$ & 0.83 & 18 (37.5) & 9 (18.7) & 0.27 & 19 (39.6) & 8 (16.6) & 0.40 \\
\hline$\geq 3.40$ & 11 (22.9) & $10(20.8)$ & & $17(35.4)$ & $4(8.3)$ & & 17 (35.4) & 4 (8.3) & \\
\hline \multicolumn{10}{|l|}{ PLR } \\
\hline$<200$ & 19 (39.6) & 11 (22.9) & 0.10 & $20(41.6)$ & $10(20)$ & 0.21 & $21(43.7)$ & 9 (18.8) & 0.30 \\
\hline$\geq 200$ & 7 (14.6) & $11(22.9)$ & & 15 (31.2) & $3(6.25)$ & & 15 (31.3) & $3(6.25)$ & \\
\hline
\end{tabular}

*Owing to the non-normal distribution of data, median used for analysis 
Out of them, only six (10\%) had well differentiated malignancy preoperatively whereas $40 \quad$ (66.7 $\%$ ) had moderately and poorly differentiated adenocarcinoma. Remaining 14 patients had diagnoses other than malignancy. However all these patients had a high suspicion of malignancy preoperatively and hence planned for surgical intervention.

Distal tumors were present in 54 patients and six patients had proximal tumors. Among these 60 patients, six patients underwent only exploration and biopsy because of the advanced disease on exploration which was not amenable to any kind of resection. Hence 54 patients underwent some form of surgery, 50 (subtotal gastrectomy and 4 total gastrectomy). Fourteen patients underwent palliative surgery because of their locally advanced disease making it unamenable for curative resection and had symptoms like bleeding and dysphagia which were not treatable endoscopically.

Surgery with curative intent was performed in 40 patients (66.7\% of total patients). Among patients who were treated with curative intent, 37 patients underwent subtotal gastrectomy and 3 underwent total gastrectomy. One of 37 patients treated with curative subtotal gastrectomy had also undergone additional procedure i.e. right hemicolectomy. Among 6 patients with proximal tumors, total gastrectomy was performed in 4 patients. Three among 4 patients treated with total gastrectomy was treated with curative intent.

Among 40 patients treated with curative intent, D2 gastrectomy was performed in 22 patients, all in patients with distal tumors; 18 underwent $\mathrm{D} 1+$ gastrectomy and 8 underwent D1 gastrectomy. Rest 6 of them underwent biopsy and gastrojjunostomy. 32 out of 50 patients with subtotal gastrectomy had Braun's jejuno-jejunal anastomosis performed.

Postoperative mean size of tumor was $4.3 \mathrm{cms}$ ( $\pm 1.94 \mathrm{cms}$ ). $31.7 \%$ had tumor size greater than $4.3 \mathrm{cms}$. As per the differentiation $11.7 \%$ had well differentiated tumors and $36.7 \%$ had poorly differentiated tumors. Among the patients who underwent curative surgery, $47.5 \%$ had moderately differentiated carcinoma and followed by poorly differentiated tumors combined.

Majority of the patients had advanced $T$ stage of the tumor, 20 (33.3\%) had T3 stage and 25 (41.7\%) had T4 disease. Distribution of T stage of tumors were $\mathrm{T} 3$ in $37.5 \%$ and $\mathrm{T} 4$ in $32.5 \%$ of the patients operated with curative intent.

Mean number of nodes retrieved was 18 (5-38) whereas mean LNR was 0.3. Majority had N2 i.e. $26(43.3 \%)$ and N3 disease i.e. 15 (25\%) as shown in table 4.

LVI was present in 35 (58.3\%) of the patients and perineural invasion was present in 36 (60\%) patients. Margin involvement was seen in5 patients. Among these five patients one had proximal margin involvement and other 4 had distal margin involvement.

The histopathological features of the operated patients were analyzed to look for association with various preoperative variables and presented in tables 5 and 6.

Preoperative variables like age, gender, preoperative CEA level, CA 19-9 level, NLR and PLR were not found to be significantly associated with the histopathological features like size of the tumor, T-stage, grade of differentiation, LNR, LVI, PNI.

Complications were seen in 24 patients. Surgical site infection was the most common complication was. Five of them had Clavien - Dindo grade 3 complications. Wound dehiscence was seen in three patients. two patients had leak of which a patient had duodenal stump leak and another had gastro-jejunostomy anastomotic leak. Total in- hospital mortality was 4 . Rest 56 patient were discharged after symptomatic improvement.

Mean hospital stay was $8.17( \pm 4.33)$ days with a range of 1-22 days.

\section{DISCUSSION}

Gastric carcinoma, despite of being the $5^{\text {th }}$ common malignancy, is reported to be in decreasing trend worldwide. But we don't have exact data to support the same for our country. It has been observed that gastric carcinoma cases are being admitted and operated in different tertiary care centres is on the rise and it holds true for our centre as well.

Median age of patients of our study group was 59 years. Majority of the patients fell into 55-60 years age group. This is in accordance with the studies from Asia however age of our study group is slightly younger than those reported in studies from west. ${ }^{21}$ Male preponderance was observed in our study group (1.22:1) which is in accordance with the SEER database. ${ }^{22}$

Most common presentation was abdominal pain. Other presenting symptoms were total or partial gastric outlet obstruction, UGI bleed, anorexia, weight loss. This was in accordance to other studies. ${ }^{23,24}$ Distal tumors were more $(90 \%)$ common than proximal tumors. This was in accordance with various studies from Asia. ${ }^{25,26}$ However proximal tumors are more common in developed countries. ${ }^{27}$ 
Consistent with the results of other studies, poorly differentiated tumors were seen more frequently in our study $(36.7 \%)$ followed by moderately differentiated tumors in $33.3 \%{ }^{28,29} \mathrm{D} 2$ gastrectomy is the standard of care. ${ }^{19}$ This is similar to the protocol at our centre. However, in our study, $55 \%$ of total patients treated with curative underwent D2 gastrectomy. There was fair proportion of patients $(45 \%)$ treated with D1 + gastrectomy with curative intent. This is because of the fact that D1+ surgery was considered adequate at surgeons' discretion considering the age, duration of surgery, blood loss and co-morbidities of the patients.

Various other studies have shown prognostic implications of CEA ${ }^{10}$, CA 19-9 11-13, NLR and PLR. High NLR and PLR have been associated with high grade tumors, higher stage of disease. ${ }^{30,31}$ It has also been associated with recurrence and overall survival as well. Unlike in most other studies, results of our study failed to show any association of preoperative CEA, CA19-9, NLR and PLR with tumor size, T stage, grade of tumors, LNR, LVI, PNI. The difference in the result of this could be small sample size as compared to most other studies.

\section{CONCLUSION}

In gastric carcinoma, advanced disease at presentation is more frequently encountered. Our study failed to show any association of preoperative CEA, CA 19-9 levels, NLR and PLR with adverse prognostic pathological features of gastric carcinoma patients.

\section{CONFLICT OF INTEREST}

None declared.

\section{ACKNOWLEDGEMENT}

To all the faculties of the department for their guidance, all the seniors and juniors for their help and all the patients who consented to participate in the study.

\section{REFERENCES}

1. World Health Organization. Global Health Observatory. Geneva: World Health Organization; 2018. who.int/gho/database/ en/. Accessed June 21, 2018.

2. Cady B, Ramsden DA, Stein A, Haggitt RC. Gastric cancer. Contemporary aspects. Am J Surg. 1977;133:423-429.

3. McBride CM, Boddie AW. Adenocarcinoma of the stomach: are we making any progress? South Med J. 1987;80:283-286.

4. Cady B, Rossi RL, Silverman ML, Piccione $W$, Heck TA. Gastric adenocarcinoma. A disease in transition. Arch Surg. 1989;124:303-308.

5. Antonioli DA, Goldman H. Changes in the location and type of gastric adenocarcinoma. Cancer. 1982;50:775-781.

6. Cidón, E.U., Bustamante, R. Gastric Cancer: Tumor Markers as Predictive Factors for Preoperative Staging. Journ Gastroint Can.2010; 42(3), 127130.

7. Park HJ, Ahn JY, Jung HY, Lim H, Lee JH, Choi $\mathrm{KS}$, et al. Clinical characteristics and outcomes for gastric cancer patients aged 18-30 years. Gastric Cancer. 2014;17(4):649-660.

8. Dilege E, Mihmanli M, Demir U, Ozer K, Bostanci $\mathrm{O}$, Kaya $\mathrm{C}$, et al. Prognostic value of preoperative CEA and CA 19-9 levels in resectable gastric cancer. Hepatogastroenterology. 2010;57(99100):674-677.

9. Ikeda $Y$, Oomori H, Koyanagi N, Mori M, Kamakura T, Minagawa S, Tateishi H, Sugimachi K. Prognostic value of combination assays for CEA and CA19-9 in gastric cancer. Oncology. 1995;52:483-6.

10. Kim DY, Kim HR, Shim JH, Park CS, Kim SK, Kim YJ. Significance of serum and tissue carcinoembryonic antigen for the prognosis of gastric carcinoma patients. J Surg Oncol. 2000;74:185-92.

11. Duraker N, Celik AN. The prognostic significance of preoperative serum CA 19-9 in patients with resectable gastric carcinoma: comparison with CEA. J Surg Oncol. 2001;76:266-71.

12. Aloe $S$, D'Alessandro $R$, Spila $A$, Ferroni $P$, Basili $S$, Palmirotta R, Carlini M, Graziano F, Mancini R, Mariotti S, Cosimelli M, Roselli M, Guadagni F. Prognostic value of serum and tumor tissue CA724 content in gastric cancer. Int J Biol Markers. 2003;18:21-7.

13. Gaspar MJ, Arribas I, Coca MC, Díez-Alonso M. Prognostic value of carcinoembryonic antigen, CA19-9 and CA72-4 in gastric carcinoma. Tumour Biol. 2001;22:318-22.

14. Ihan $N$, Ilhan $Y$, Akbulut $H$, Kucuksu $M$. C-reactive protein, procalcitonin, interleukin-6, vascular endothelial growth factor and oxidative metabolites in diagnosis of infection and staging in patients with gastric cancer. World Journal of Gastroenterology: WJG 2004; 10(8): 1115-20.

15. Kim DK, On SY, Kwon HC, Lee S, Kwon KA, Kim $B G$, et al. Clinical significances of preoperative serum interleukin-6 and C-reactive protein level in resectable gastric cancer. BMC Cancer 2009; 9: 155.

16. Kilincalp S, Ekiz F, Basar O, Ayte MR, Coban $S$, Yilmaz $B$, et al. Mean platelet volume could be possible biomarker in early diagnosis and monitoring of gastric cancer. Platelets 2014; 25(8): 592-4.

17. Aldemir MN, Turkeli $M$, Simsek M, Yildirim N, Bilen $Y$, Yetimoglu $H$, Bilici $M$, Tekin SB. Prognostic Value of Baseline Neutrophil-Lymphocyte and PlateletLymphocyte Ratios in Local and Advanced Gastric Cancer Patients. Asian Pac J Cancer Prev. 
2015;16(14):5933-7.

18. Lian, L., Xia, Y.-Y., Zhou, C. et al. Application of platelet/lymphocyte and neutrophil/lymphocyte ratios in early diagnosis and prognostic prediction in patients with resectable gastric cancer. Cancer Biomarkers, 15(6), 899-907.

19. Japanese Gastric Cancer Association Japanese gastric cancer treatment guidelines 2014 (ver. 4) Gastric Cancer. 2017;20(1):1-19

20. Scheidbach $H$, Lippert $H$, Meyer F. Gastric carcinoma: when is palliative gastrectomy justified? Oncol Rev. 2010;4(2):127-132.

21. American Cancer Society. What are the key statistics about stomach cancer? [Internet]. Atlanta (GA): American Cancer Society; 2017.

22. Wu H, Rusiecki JA, Zhu K, Potter J, Devesa SS. Stomach carcinoma incidence patterns in the United States by histologic type and anatomic site. Cancer Epidemiol Biomarkers Prev 2009.

23. Maconi G, Manes G, Porro GB. Role of symptoms in diagnosis and outcome of gastric cancer. World J Gastroenterol 2008;14:1149-55.

24. Safaee A, Moghimi-Dehkordi B, Fatemi SR, Ghiasi S, Pourhoseingholi MA, Zali MR. Clinicopathological Features of Gastric Cancer: A Study Based on
Cancer Registry Data. IJCP 2009;2:67-70.

25. Sharma A, Radhakrishnan V. Gastric cancer in India. Indian J Med Paediatr Oncol 2011;32:12-16.

26. Zheng L, Wu C, Xi P, Zhu M, Zhang L, Chen S, et al. The survival and the long-term trends of patients with gastric cancer in Shanghai, China. BMC Cancer 2014;14:300.

27. Alberts SR, Cervantes A, van de Velde CJ. Gastric cancer: epidemiology, pathology and treatment. Ann Oncol 2003;14 Suppl 2:ii31-ii36.

28. Kim DY, Ryu SY, Kim YJ, Kim SK. Clinicopathological characteristics of gastric carcinoma in young patients. Langenbecks Arch Surg 2003;388:2459.

29. Nakamura T, Yao T, Niho Y, Tsuneyoshi M. A clinicopathological study in young patients with gastric carcinoma. J Surg Oncol 1999;71:214-9.

30. Mohri Y, Tanaka K, Ohi M, et al (2010). Prognostic significance of host-and tumor-related factors in patients with gastric cancer. World J Surg, 34, 285-90.

31. Jung MR, Park YK, Jeong O, et al (2011). Elevated preoperative neutrophil to lymphocyte ratio predicts poor survival following resection in late stage gastric cancer. J Surg Oncol, 104, 504-10. 